\title{
Optimization of SiCp Surface and Interface Structure of SiCp/A390 Composites
}

\author{
Ai-qin Wang ${ }^{a} 1,2,{ }^{*}$, Hui-dan Guo ${ }^{b 1,2}$, Min Lic 3 , Jing-pei Xie ${ }^{d 1,2}$, and Dou-qin \\ $\mathrm{Ma}^{\mathrm{e} 1,2}$ \\ ${ }^{1}$ College of Material Science and Engineering, Henan University of Science and Technology, \\ Luoyang 471023, China, \\ ${ }^{2}$ Collaborative Innovation Centers of Non-Ferrous Materials, Henan Province, Luoyang 471023, \\ China, \\ ${ }^{3}$ Shine Tech CO., LTD Zhejiang Province, Zhejiang Province, Jiaxing 314000, China. \\ aaiqin_wang888@163.com \\ ${ }^{*}$ Corresponding author
}

Keywords: Composite Materials, Surface Modification, Powder Metallurgy Method, Interface Structure, Interface Reaction

\begin{abstract}
SiCp} / \mathrm{A} 390$ (SiC particle reinforced $\mathrm{Al}$ matrix) composites before and after SiC particles surface modification were manufactured respectively by powder metallurgy, and the mass fraction of $\mathrm{SiCp}$ is $20 \%$. The surface morphology of $\mathrm{SiCp}$ and the interface morphology of $\mathrm{SiC} / \mathrm{Al}$ and $\mathrm{SiC} / \mathrm{Si}$ of composites were characterized by TEM. The chemical state of interface material of $\mathrm{SiCp} / \mathrm{A} 390$ composites was tested by XPS. The effect of surface modification of SiCp on interface structure of composites and thermodynamic principle of mechanism of interface formation of $\mathrm{SiCp} / \mathrm{A} 390$ were researched. The results show that SiCp morphology was changed though surface optimization treatment, the dense $\mathrm{SiO}_{2}$ oxide layer on the surface of $\mathrm{SiCp}$ was formed when $\mathrm{SiC}$ particles were roasted at $1000^{\circ} \mathrm{C}$, which thickness membrane is about $50 \mathrm{~nm}$. Before $\mathrm{SiC}$ particles surface modification, the interface of $\mathrm{SiC} / \mathrm{Al}$ of composites is clear, clean interface, and discovered a small amount of amorphous layer interface of $\mathrm{SiC} / \mathrm{Al}$. While, after SiC optimization, the interface of $\mathrm{SiC} / \mathrm{Al}$ of composites is an amorphous layer between two phases, and there is no $\mathrm{Al}_{4} \mathrm{C}_{3}$ in $\mathrm{SiCp} / \mathrm{A} 390$ composites. Surface modification treatment of SiCp can increase chemical reaction degree of the interface of composites, and effectively improve the interface bonding of $\mathrm{SiC}$ and $\mathrm{Al}$.
\end{abstract}

\section{Introduction}

$\mathrm{SiCp}$ reinforced Al metal matrix composites present a remarkable combination of outstanding advantages, such as low density and good dimensional stability, high elastic modulus, and are widely applied in spacecrafts, military industry and electronic components as lightweight structural materials [1].Over the last two decades, the medium volume fraction $\mathrm{SiCp} / \mathrm{Al}$ composites have become a hot spot research [2-3]. The composition and microstructure of composite materials decide materials performance. As a carrier of load, the interface between reinforced particles and matrix in composite materials has played a vital role on the performance of the composite material. The interface characteristics of the specific component composite materials would be affected by the morphology of reinforced particle, surface properties, preparation methods of composite materials and heat treatment process, etc. In order to control harmful interface reaction, $\mathrm{SiC}$ reinforced particles were preprocessed by some methods, when $\mathrm{SiCp} / \mathrm{Al}$ composite material was prepared using liquid phase or semi-solid method. In several pretreatment methods of SiCp, the effects of dilute $\mathrm{HCl}$ wash and high temperature oxidation were better, and the reports about them were more. Guo Jian[4] et al. have studied the effect of pre-heating processing of SiC particles on porosity of $\mathrm{SiCp} / \mathrm{Al}$ composites, which are manufactured by stirring casting composition means, by heating $\mathrm{SiCp}$ at $600{ }^{\circ} \mathrm{C}$ and heat preservation for $3 \mathrm{~h}$. And they found that $\mathrm{SiCp}$ after oxidation treatment is uniform distributed in $\mathrm{SiCp} / \mathrm{A} 1$ composites, interfaces divide into two kinds: clean 
interface and mild reaction interface, meanwhile avoiding the generation of harmful interface product $\mathrm{A}_{4} \mathrm{C}_{3}$. Wang Chuan-ting [5] et al. studied the influence of SiCp oxidation on the wettability and interface bonding of composite material which are prepared by casting, and found that When $\mathrm{SiCp}$ is heated at $800-1100{ }^{\circ} \mathrm{C}$, a certain thickness layer of $\mathrm{SiO}_{2}$ forms on its surface. And interface reaction will form between melt aluminum and oxide layer under high temperature, which can improve the interfacial wettability, make the interface combination to be better. Meanwhile, $\mathrm{MgAl}_{2} \mathrm{O}_{4}$ and $\mathrm{Mg}_{2} \mathrm{Si}$ generate near the interface, and no harmful product $\mathrm{Al}_{4} \mathrm{C}_{3}$ founded.

Many investigations about the pretreatment technology of SiCp have been reported. However, the research about microstructure change and phase composition of SiCp surface before and after oxidation and interface microstructure evolution of $\mathrm{SiCp} / \mathrm{Al}-\mathrm{Si}$ composite by powder metallurgy have been rarely reported [6]. In this article, the morphology and the surface phase chemical composition of SiCp under different processing methods have been characterized by TEM and XPS, and the interface materials chemical state of SiCp/A390 composites was also tested by XPS. In those contexts, the influence of SiCp surface optimization on interface structure of SiCp/A390 composites and the principle forming the thermodynamic mechanism of composite interface have been studied deeply. Overall, the aim of this paper is to provide the theoretical basis engineering application and technical support for lightweight, low expansion and high strength aluminum matrix composites.

\section{Materials and Methods}

The matrix alloy used in this investigation is $\mathrm{A} 390$ (wt19.3\% $\mathrm{Si}, 1.2 \% \mathrm{Cu}, \mathrm{Mg}, 0.8 \% \mathrm{Mg}, 0.5 \%$ $\mathrm{Ni}$ ) and reinforcement is $\mathrm{SiC}$ particle. The average particle size of $\mathrm{A} 390$ alloy power and $\mathrm{SiC}$ particles is $10 \mu \mathrm{m}$ and $5 \mu \mathrm{m}$, respectively. The volume fraction of SiC particles in the composites is $20 \%$. After water washing processing, in order to remove impurity (instance water vapor and carbon element), SiCp would be heated to $650{ }^{\circ} \mathrm{C}$ and kept for $2 \mathrm{~h}$, and then weighed. SiC particles were calcinated at a temperature of $1000{ }^{\circ} \mathrm{C}$ in a high temperature oxidation furnace, with a heating rate of $10^{\circ} \mathrm{C} / \mathrm{min}$, holding time of $6 \mathrm{~h}$. To ensure the high temperature oxidation reaction conduct adequately, furnace would be opened for oxygenating every half hour during roasting. Then, used the QM - BP type planetary ball mill, the A390 alloy power and SiC particles were ball-mixed in a high-speed planetary mill for $4 \mathrm{~h}$ with the rotation speed of $250 \mathrm{rpm}$, and the weight ratio of ball and powder was $2: 1$. Then the mixtures (about $100 \mathrm{~g}$ ) were pressed by employing TTD32 four-column hydraulic, with a pressure of $200 \mathrm{MPa}$, holding time of $50 \mathrm{~min}$, unloading time of 20 min. First, the semi-finished products were sintered in the nitrogen protection furnace by furnace cooling, with a heating rate of $2{ }^{\circ} \mathrm{C} / \mathrm{min}$, holding temperature of $560{ }^{\circ} \mathrm{C}$, holding time of $3 \mathrm{~h}$. Next, the sintered lumps were extruded by XJ-500 metal profile extrusion machine, with an extrusion ratio of $15: 1$, extrusion temperature of $480{ }^{\circ} \mathrm{C}$, extrusion speed of $1 \mathrm{~mm} / \mathrm{s}$. At last the $\mathrm{SiCp} / \mathrm{Al}$ composite materials were dealt with annealing treatment at the temperature of $400{ }^{\circ} \mathrm{C}$ for $2 \mathrm{~h}$. Microstructure was observed by transmission electron microscopy (TEM) and the material phase chemical state of SiCp surface before and after oxidation and composite material interface structure was studied by X-ray photoelectron spectroscopy (XPS). Analyses on the surface optimization of $\mathrm{SiC}$ particles and its effect of interface structure of $\mathrm{SiCp} / \mathrm{A} 390$ composites were carried out.

\section{Results and Discussion}

\section{Microstructure and Chemical State Analysis of SiC Particle Surface}

TEM images and the corresponding diffraction pattern of original and treated SiC particle surface are shown in Fig.1. It can be seen that the original SiC particle surface was clean, with relatively obvious edges and corners. Its contrasts obvious and is the typical crystal structure, seen Fig.1 (a). The original state SiCp diffraction pattern was calibrated as close the six-party $\alpha$-SiC, space group as P63mc (186), the lattice constant for $\mathrm{a}=3.081 \AA$, $\mathrm{c}=15.120 \AA$, each (001) crystal plane containing six stacking, its orders for $\mathrm{ABCACB}$, each stacking interplanar spacing as $0.25 \mathrm{~nm}$. 
Anther diffraction pattern of $\mathrm{SiCp}$ in the test was the cubic system $\beta$-SiC, space group for $\mathrm{F}-43 \mathrm{~m}$ (216), the lattice constant for $\mathrm{a}=4.359 \AA$, stacking order for ABCABC...... The treated SiC particle surface is smoother compared with that of original SiC particle surface, as shown in Fig.1 (b). And a thickness of $50 \mathrm{~nm}$ material is generated on the particle's surface, and its diffraction spot is dizzy ring, indicating that the material is amorphous, which convicted preliminary to be $\mathrm{SiO}_{2}$ according to the thermodynamic information of SiCp.
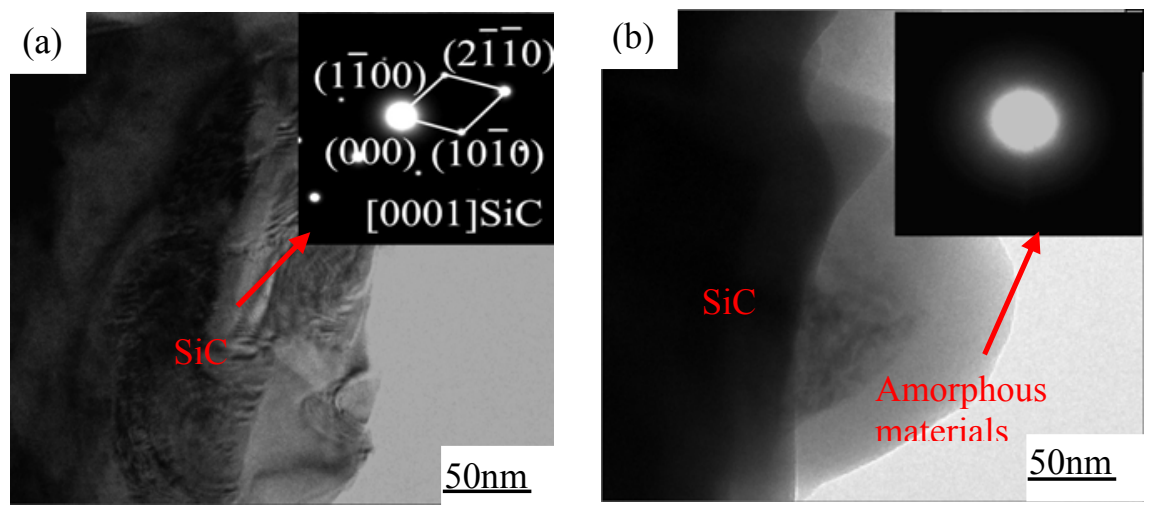

Fig.1TEM of and diffraction pattern of SiC particles

(a) TEM original state SiC particles, (b) TEM and diffraction pattern of oxidized SiC particles

The material could not be detected by XRD when the content is less than a certain value, so XPS was carried out to identify the material compositions on the SiC particle surface. SiCp was analyzed all the components after vacuum treatment, then Si element was scanned accurately. XPS data was analyzed using Multipak peak software, correction data in a standard free $\mathrm{C}$ with the binding energy of $284.6 \mathrm{eV}$ points, peaking and fitting each element separately again. Fig.2b shows the XPS survey spectrum of original SiC particulates. Three peaks were appeared in the full spectrum, peak 100.2 $\mathrm{eV}, 101.3 \mathrm{eV}$ and $100.2 \mathrm{eV}$ after data fitting. According to the NIST XPS Database, standard binding energy of $\mathrm{SiC}$ and $\mathrm{Si}$ are $100.1 \mathrm{eV}$ and $101.3 \mathrm{eV}$, respectively. Thus, the original state of $\mathrm{SiC}$ surface has no $\mathrm{SiO}$, which mainly existed in the form of $\mathrm{SiC}$ and handful instability $\mathrm{SiO}$, shown as Fig. 1. Fig. $2 \mathrm{~b}$ shows the XPS survey spectrum of original SiC particulates. By Si $2 \mathrm{p}$ line of surface optimization SiCp, The binding energies of peaks are located at $101.5 \mathrm{eV}$ and $103.6 \mathrm{eV}$, which correspond to the standard binding energy of $\mathrm{SiC}$ and $\mathrm{SiO}$ for $101.3 \mathrm{eV}$ and $103.4 \mathrm{eV}$. Therefore, it can be concluded that $\mathrm{Si}$ in the reaction layer mainly existed in the form of the $\mathrm{SiO}$ and $\mathrm{SiO} 2$, and $\mathrm{SiO} 2$ peak area was biggest. From peaking and fitting analysis results, mole ratio of atom of $\mathrm{SiO}_{2}$ and the $\mathrm{SiO}$ was 96.31:3.69. So the reactant of surface optimization $\mathrm{SiCp}$ mainly was $\mathrm{SiO}_{2}$.
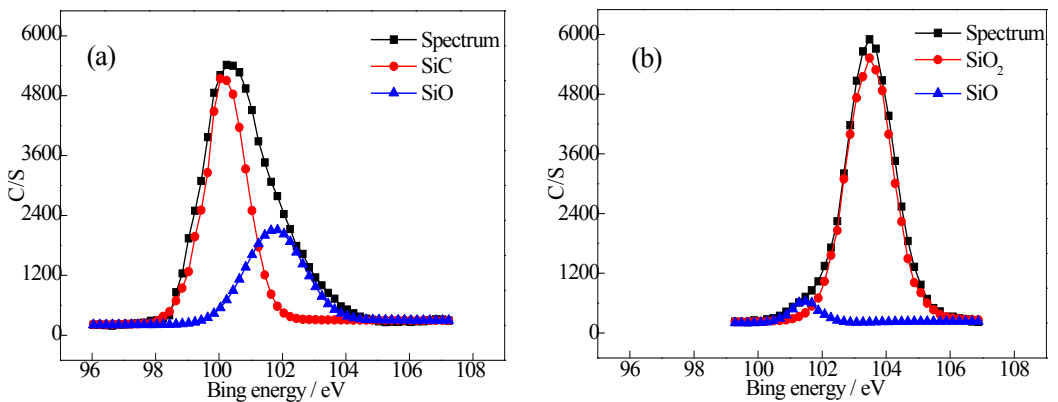

Fig.2 XPS analysis of SiC particles

(a) Si2P peak of original $\mathrm{SiC}$ particles; (b) Si2P peak of oxidized $\mathrm{SiC}$ particles 


\section{Influence of Surface Optimization of SiCp on Interface of SiCp/A390 Composite}

The interface between the $\mathrm{SiC}$ and $\mathrm{A} 390$ of $\mathrm{SiCp} / \mathrm{A} 390$ composites, which prepared by powder metallurgy with solid solution and aging treatment, was observed by TEM, shown as Fig.3. By plenty of observation showed that, there are two main types interface of the original state $\mathrm{SiCp} / \mathrm{A} 390$ composite. The interface is clean and smooth, and there are no obvious interface chemical reaction and particle dissolution phenomena as well as cavity defects, seen Fig.3 (a). Fig.3 (b) shows another interface type is amorphous type interface, which existing several nanometers wide interface layer between the matrix and the reinforcement. The thermal expansion coefficient of SiCp and Al respectively were $4.7 \times 10^{-6}{ }^{\circ} \mathrm{C}^{-1}$ and $25 \times 10^{-6}{ }^{\circ} \mathrm{C}^{-1}$ at room temperature. Al matrix near $\mathrm{SiCp}$ has a high density of dislocations due to the vast different thermal expansion coefficient between the SiCp and Al. The thermal stress between matrix and strengthen body was produced because of large deformation, or large temperature difference from high temperature cooling to room temperature, during the preparation of composite materials. And dislocation loops are released to Al matrix, which forming a large number of dislocations, when thermal stress exceeded the yield strength of the matrix. Fig.3 (c) shows the clean interface of $\mathrm{SiC} / \mathrm{Si}$ of original state composite. Si precipitation is precipitated when composite materials are sintered, which forming a large number of $\mathrm{SiC}$ and $\mathrm{Si}$ interface, and the interface is clean, flat and no obvious interface reaction, shown as Fig.3 (c). The diffraction patterns of $\mathrm{Al}_{4} \mathrm{C}_{3}$ and $\mathrm{MgAl}_{2} \mathrm{O}_{4}$ as described in the literature [7, 8] haven't been found in SiC/Al interface of original state SiCp/A390 composites. Maybe, this interface reaction can't occur because of low temperature during powder metallurgy process, or the matter content was less special. Therefore, that should go on further research.

Based on plenty of comparison and analysis, SiC/Al interface of SiCp/A390 composites are also divided into two types after interface optimization processing. The one is an amorphous layer interface, accounted for the vast majority in the surface optimization SiCp/A390 composites, which has about $5 \mathrm{~nm}$ interface thickness between $\mathrm{Al}$ and $\mathrm{SiC}$, seen Fig.3 (d). Another is obvious reactive interface, which has about $10 \mathrm{~nm}$ reaction interfaces between $\mathrm{Al}$ and $\mathrm{SiC}$, shown as Fig.3 (e). It is too difficult to select the appropriate area to diffract the analysis interface structure since the interface zone width is small. A density $\mathrm{SiO} 2$ layer is founded on the optimization surface of $\mathrm{SiCp}$, and it can react with $\mathrm{Al}$ and $\mathrm{Mg}$ (which is easily gathered at the interface) to generate magnesium aluminum spine (MgAl2O4), according to the research of LiuPei [9].

As shown in Fig.3 (f), the interface of $\mathrm{SiC}$ and $\mathrm{Si}$ in optimization $\mathrm{SiCp} / \mathrm{A} 390$ composites is also clean interface type. Namely, the surface optimization of SiCp changes the interface structure type of SiCp/A390 composites. The clean interface of most of the original SiCp / A390 composites is converted into the amorphous interface of the oxidation state. The surface optimization of SiCp was less effect on the interface structure type of $\mathrm{SiC}$ and $\mathrm{Si}$ interface of $\mathrm{SiCp} / \mathrm{A} 390$ composite. SiC particles stating in the optimum conditions have little effect on the interface in composite materials.
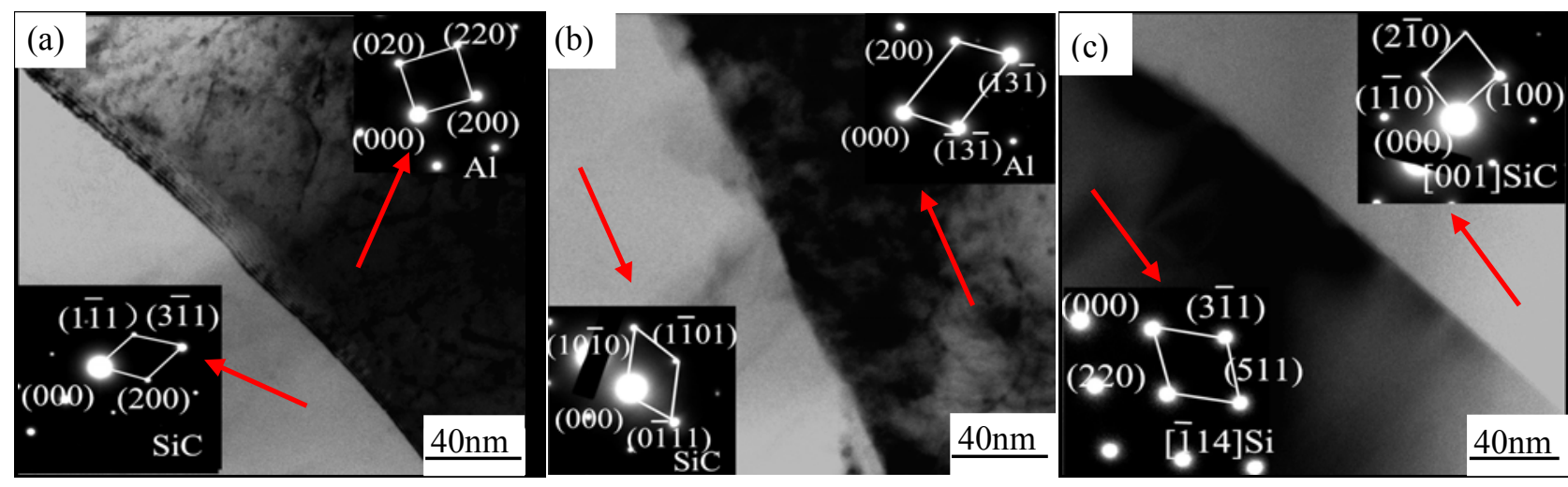

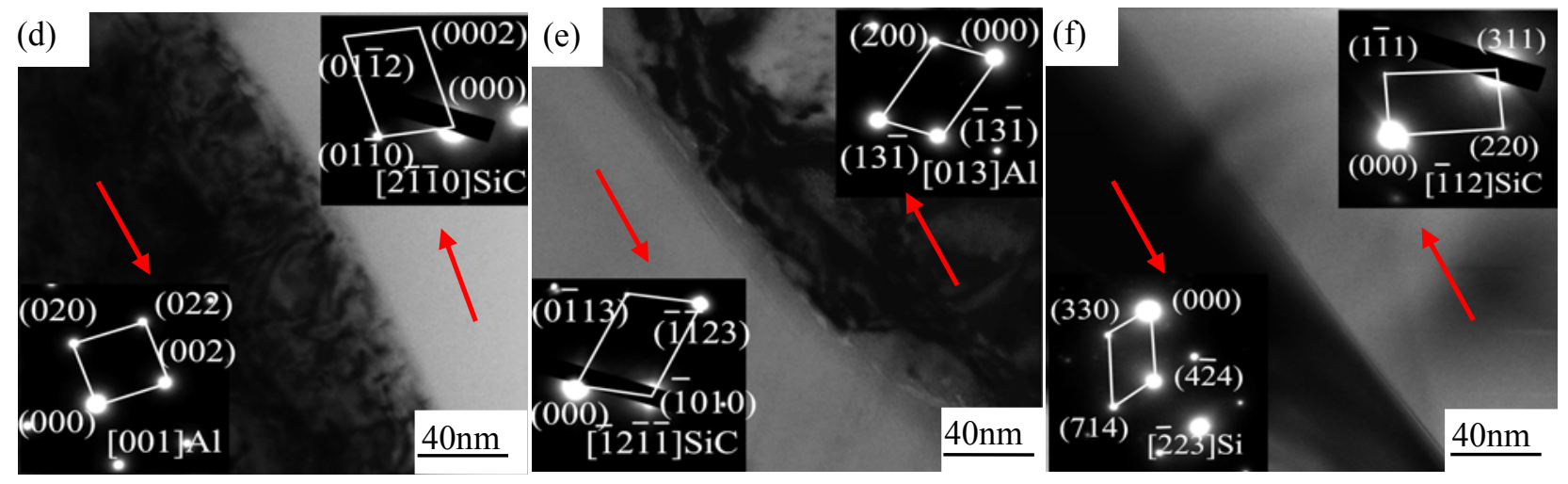

Fig.3 TEM of SiC/A390 composites;

(a) The clean interface of $\mathrm{SiC} / \mathrm{Al}$ of original state composite; (b) The amorphous interface SiC/Al of original state composite; (c) The clean interface of $\mathrm{SiC} / \mathrm{Si}$ of original state composite; (d) The amorphous interface of $\mathrm{SiC} / \mathrm{Al}$ of oxidized state composite; (e) The reaction interface of SiC/Al of oxidized state composite; (f) The clean interface of

$\mathrm{SiC} / \mathrm{Si}$ of oxidized state composite

\section{Effect of Surface Optimization Chemical Speciation of Interface Materials of SiCp/A390 Composites}

TEM analysis has certain limitations to test a small amount of interface material, so it is better use X-ray photoelectron spectroscopy (XPS) analysis to explore the formation mechanism of the interface microstructure and composite interface bonding mechanism [9]. Full spectrum diagram (Fig.4 (b)) of original state SiCp/A390 composites shows that element Al, Si and C, O exist on the fracture interface, $\mathrm{Mg}$ element is relatively small, and is not shown. From $2 \mathrm{p}$ points peak fitting chart of $\mathrm{Al}$, there are two peaks at $72.8 \mathrm{eV}$ and $74.6 \mathrm{eV}$, its corresponding the binding energy of $\mathrm{Al}$ ( $2 \mathrm{p}$ peak combined energy is $72.6 \mathrm{eV}$ ) and $\mathrm{Al}_{2} \mathrm{O}_{3}(2 \mathrm{p}$ peak combined energy is $74.4 \mathrm{eV}$ ) according to the NIST XPS Database. XPS test on the material surface chemical state can qualitative analysis, content can be semi-quantitative analysis, shows the ratio of $\mathrm{Al}$ and $\mathrm{Al}_{2} \mathrm{O}_{3}$ is 91:9. Brittle phase $\mathrm{Al}_{4} \mathrm{C}_{3}$ (its $2 \mathrm{p}$ peak combined energy is $73.6 \mathrm{eV}$ ) in the spectrogram has not been found, probably because the sintering temperature in powder metallurgy method relative to the liquid phase method is low, and harmful interface reaction doesn't produce. Oxygen in the $\mathrm{Al}_{2} \mathrm{O}_{3}$ may come from the substrate A390 alloy powders, not the interface enhancement and chemical reaction according to TEM (Fig.1 (a,b)) of the surface of original state SiCp, and a small amount of the amorphous interface in the composite (Fig. 3b) may be the $\mathrm{Al}_{2} \mathrm{O}_{3}$ that formed by oxidation of matrix alloy. There are two peaks at $99.9 \mathrm{eV}$ and $100.4 \mathrm{eV}$, respectively corresponding to the binding energy of $\mathrm{Si}$ ( $2 p$ peak combined energy was $99.8 \mathrm{eV}$ ) and $\mathrm{SiC}(2 \mathrm{p}$ peak combined energy is $100.4 \mathrm{eV}$ ) by $2 \mathrm{p}$ points peak fitting chart of Si (Fig. 5(c)), namely, the existence form of Si are Si that separate out and $\mathrm{SiC}$.
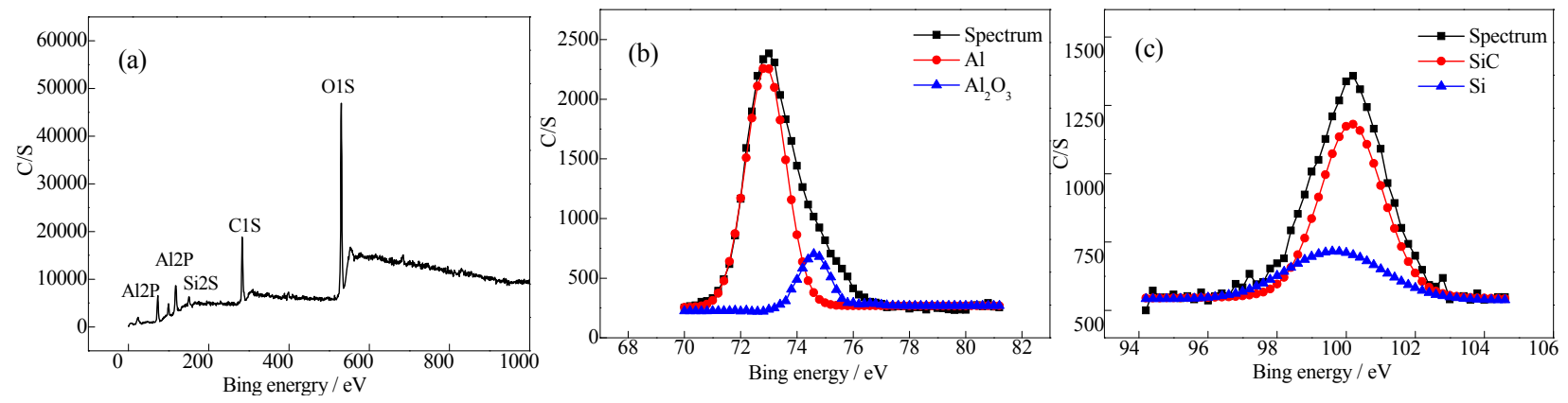

Fig.4 XPS analysis of interface materials of the original SiCp/A390 composites

(a) spectrum of the original $\mathrm{SiCp} / \mathrm{A} 390 ;$ (b)A12P peak of original SiCp/A390; (c) Si2P peak of original SiCp/A390;

(d)Mg2P peak of original $\mathrm{SiCp} / \mathrm{A} 390$ 

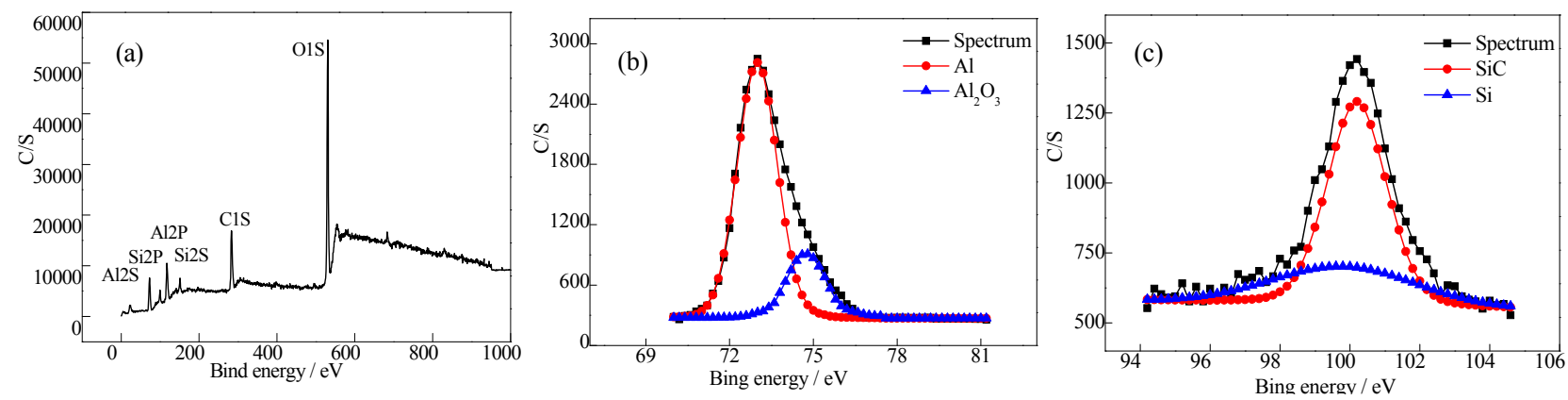

Fig.5 XPS analysis of interface materials of the oxidation $\mathrm{SiCp} / \mathrm{A} 390$ composites

(a) spectrum of the oxidation SiCp/A390; (b)Al2P peak of oxidation SiCp/A390; (c) Si2P peak of oxidation SiCp/A390; (d)Mg2P peak of oxidation $\mathrm{SiCp} / \mathrm{A} 390$

Fig.5 shows the interface of surface modification composites analyzed by XPS. The interface main element of the $\mathrm{SiCp} / \mathrm{A} 390$ composites that surface modification are $\mathrm{Al}, \mathrm{Si}$ and $\mathrm{C}, \mathrm{O}$ by all the component spectra (Fig.5(a)). The spectral peaks are $74.8 \mathrm{eV}$ and $73.0 \mathrm{eV}$ by $2 p$ spectral line of $\mathrm{Al}$ (Fig.5b), contrast NIST XPS Database, the standard binding energy of $\mathrm{Al}$ in $\mathrm{Al}_{2} \mathrm{O}_{3}$ was $74.4 \mathrm{eV}$, and the $2 \mathrm{p}$ standard binding energy of $\mathrm{Al}$ is $72.6 \mathrm{eV}$, then the existence form of $\mathrm{Al}$ element at the interface for $\mathrm{SiCp} / \mathrm{A} 390$ composites after surface modification are $\mathrm{Al}$ and $\mathrm{A} 12 \mathrm{O} 3$. The content ratio of $\mathrm{Al}$ and $\mathrm{Al}_{2} \mathrm{O}_{3}$ content on the interface is $83: 17$ through semi-quantitative analysis. So the quantity of $\mathrm{Al}_{2} \mathrm{O}_{3}$ increases obviously at the interface through contrast the strength of the peak shown as Fig. 5(b) and Fig.5 (b), and the process of surface modification of SiCp made the obviously chemical reaction at the interface, which will be conducive to the combination of reinforced particles and matrix, increased the strength of composite material interface. Interface reactant $\mathrm{MgAl}_{2} \mathrm{O}_{4}(2 \mathrm{p}$ peak combined energy is $75.7 \mathrm{eV}$ ) has not been found in Fig.5 (b), because the content is too little compared with Al and A12O3, and it can't be detected by XPS. Fig. 6 (c) shows the 2P accurate scanning lines of $\mathrm{Si}$ in $\mathrm{SiCp} / \mathrm{A} 390$ composites, the corresponded binding energy values of two peaks are $100.5 \mathrm{ev}$ and $99.9 \mathrm{ev}$. The corresponded value of standard spectrum peak and the $2 \mathrm{p}$ standard spectrum peak of $\mathrm{Si}$ in the $\mathrm{SiC}$ are $100.4 \mathrm{eV}$ and $99.8 \mathrm{eV}$, respectively. Si exists mainly as $\mathrm{SiC}$ and elemental Si, which can be obtained by Fig.5(c). So the oxide layer on surface modification $\mathrm{SiCp}$ is fully participated in interfacial chemical reaction, forming $\mathrm{Al}_{2} \mathrm{O}_{3}$ and $\mathrm{MgAl}_{2} \mathrm{O}_{4}$.

\section{Interface Formation Mechanism of Surface Modification Composites}

SiCp was preceded by $1000{ }^{\circ} \mathrm{C}$ and $6 \mathrm{~h}$ high temperature oxidation treatment to reach surface modification, and the particles surface arise $\mathrm{SiO}_{2}$ oxide layer, which is about $50 \mathrm{~nm}$. The weighing method and formulas calculate the oxygen contents in the oxidation process. The oxygen contents before oxidation is $99.1327 \mathrm{~g}$ and after oxidation is $101.2891 \mathrm{~g}$. Oxygen ration of SiCp after surface modification can calculate according to the molecular weight $\mathrm{SiC}, \mathrm{SiO}_{2}$ and $\mathrm{O}_{2}$ is $40.99 \mathrm{~g} / \mathrm{mol}$, $60.08 \mathrm{~g} / \mathrm{mol}$ and $32 \mathrm{~g} / \mathrm{mol}$, respectly. The calculation process is $(101.2891-99.1327) \times 32 /(60.08-40.99) / 101.2891 \times 100=3.5687 \%$.

Table 1 Possible chemical reactions in the interface between $\mathrm{SiC}$ and $\mathrm{Al}$ [12]

\begin{tabular}{lll}
\hline Chemical reaction equations & $\begin{array}{l}\text { Enthalpy change } \Delta \mathrm{G}^{0} \\
(\mathrm{~J} / \mathrm{mol})\end{array}$ & $\begin{array}{l}\Delta \mathrm{G}^{0}(\mathrm{~J} / \mathrm{mol}) \\
833.15 \mathrm{~K}\end{array}$ \\
\hline$(1) 3 \mathrm{SiO}_{2}(\mathrm{~s})+2 \mathrm{MgO}(\mathrm{s})+4 \mathrm{Al}(\mathrm{l})=2 \mathrm{Mg} \mathrm{Al}_{2} \mathrm{O}_{4}(\mathrm{~s})+3 \mathrm{Si}(\mathrm{l})$ & $-790467+77.96 \mathrm{~T}$ & -725514.63 \\
$(2) 2 \mathrm{SiO}_{2}(\mathrm{~s})+2 \mathrm{Al}(\mathrm{l})+\mathrm{Mg}(\mathrm{l})=\mathrm{MgAl}_{2} \mathrm{O}_{4}(\mathrm{~s})+2 \mathrm{Si}(\mathrm{l})$ & $-558519+56.69 \mathrm{~T}$ & -511287.85 \\
$(3) 3 \mathrm{SiO}_{2}(\mathrm{~s})+4 \mathrm{Al}(\mathrm{l})=2 \mathrm{Al}_{2} \mathrm{O}_{3}(\mathrm{~s})+3 \mathrm{Si}(\mathrm{l})$ & $-719292+83.90 \mathrm{~T}$ & -649390.96 \\
$(4) \mathrm{SiO}_{2}(\mathrm{~s})+2 \mathrm{Mg}(\mathrm{l})=2 \mathrm{MgO}(\mathrm{s})+\mathrm{Si}(\mathrm{l})$ & $-326570+35.42 \mathrm{~T}$ & -297060.23 \\
$(5) \mathrm{Si}(\mathrm{l})=\mathrm{Si}(\mathrm{s})$ & $-50630+30.08 \mathrm{~T}$ & -25568.85 \\
$(6) \mathrm{SiC}(\mathrm{s})=\mathrm{Si}(\mathrm{l})+\mathrm{C}(\mathrm{s})$ & $123470-37.57 \mathrm{~T}$ & 92168.55 \\
$(7) 3 \mathrm{SiC}(\mathrm{s})+4 \mathrm{Al}(\mathrm{l})=\mathrm{Al}_{4} \mathrm{C}_{3}(\mathrm{~s})+3 \mathrm{Si}(\mathrm{l})$ & $103900-16.48 \mathrm{~T}$ & 90169.69 \\
\hline
\end{tabular}


The composite materials' sintering temperature is $560^{\circ} \mathrm{C}$ which closes to the solidus temperature, which makes preparation process presenting a small amount of liquid. According to the analysis of infiltration and diffusion principle, the chemical reaction between $\mathrm{Mg}$, which appear in the boundary, $\mathrm{SiO}_{2}$, which present in the surface of $\mathrm{SiCp}$, and $\mathrm{Al}$ matrix.The chemical reaction equation Gibbs free enthalpy and reaction process are shown in Table 1 . Those reactions are possible since the gibbs free enthalpy of reaction equation (1-5) is negative. The gibbs value of reactions (6 and 7) is positive, so those reactions are impossible. There is no $\mathrm{Al}_{4} \mathrm{C}_{3}$ found by $\mathrm{XRD}$ and TEM test, which also verify that these reactions can't be carried out. The gibbs free energy of reaction equation (1-4) under the experiment condition is $-725.5 \mathrm{KJ} / \mathrm{mol}$ and $-511.2 \mathrm{KJ} / \mathrm{mol},-649.4 \mathrm{KJ} / \mathrm{mol}$ and $-297.1 \mathrm{KJ} / \mathrm{mol}$, respectively. If $\mathrm{MgO}$ exist on interface, chemical reaction (1) will preferentially occur, then the chemical reaction (2-3) follow. Meanwhile, the presence of reactive interface is confirmed from the perspective of thermodynamics. SiCp surface is covered a $\mathrm{SiO}_{2}$ oxide layer after surface modification. During the preparation process, $\mathrm{Al}$ element and $\mathrm{Mg}$ element diffusion and enrichment on the surface of $\mathrm{SiCp}$, which with $\mathrm{SiO} 2$ layer can promote the good combination between $\mathrm{Al}$ matrix and $\mathrm{SiCp}$. The $\mathrm{O}_{2}$ content is $0.7137 \mathrm{~g}$ for $\mathrm{SiCp} / \mathrm{A} 390$ composites ( $\mathrm{SiCp}$ is $20 \%$ ) after surface modification, only requires $\mathrm{O}_{2} 0.1338 \mathrm{~g}$. It is indicated that the oxide film on the surface of reinforced particles in composite materials can fully reflect off under ideal conditions, and there is no $\mathrm{SiO} 2$, shown as Fig.5 (c).

\section{Conclusions}

1) Before SiC particles surface modification, the interface of $\mathrm{SiC} / \mathrm{Al}$ of composites is clear, clean, flat, no hole defect, and discovered a small amount of amorphous layer interface of SiC/Al. Surface modification treatment not only can change the surface morphology of SiCp, but also make the dense $\mathrm{SiO}_{2}$ layer formed on the surface, which is about $50 \mathrm{~nm}$. Very little $\mathrm{SiO}$ but no $\mathrm{SiO}_{2}$ can be observed on the surface of the original state $\mathrm{SiCp}$.

2) Surface modification made $\mathrm{SiC} / \mathrm{Al}$ surface based amorphous type interface that obvious interface layers, and there is no $\mathrm{Al}_{4} \mathrm{C}_{3}$ in $\mathrm{SiCp} / \mathrm{A} 390$ composites. Surface modification treatment of $\mathrm{SiCp}$ has little influence on the type of $\mathrm{SiC} / \mathrm{Si}$ surface.

3) Surface modification treatment of SiCp can increase chemical reaction degree of the interface of composites, and effectively improve the interface bonding of $\mathrm{SiC}$ and $\mathrm{Al}$.

\section{Acknowledgement}

This work is supported by the Education Department of Henan Province (grant no. 13A430262)

\section{References}

[1] L.H. Zou, J.Z. Fan, T. Zuo, et al. High-cycle fatigue behavior of 15\%SiCp/2009Al composite prepared by powder metallurgy process[J].The Chinese Journal of Nonferrous Metals, 20 (2010) $1955-1961$.

[2] D. Mandal, S. Viswanathan. Effect of heat treatment on microstructure and interface of SiC particle reinforced 2124 Al matrix composite [J]. Materials Characterization, 85 (2013) 73-81.

[3] A. Bahrami, M.I. Pech-Canul, C.A. Gutierrez, N. Soltani. Effect of rice-husk ash on properties of laminated and functionally graded $\mathrm{Al} / \mathrm{SiC}$ composites by one-step pressureless infiltration, 2015, Journal of Alloys and Compounds, 644 (2015) 256-266.

[4] J. Guo, X.B. Liu. Effect of pre-heating processing of SiC particles on porosity of SiCp/Al composites [J].Transactions of Materials and Heat Treatment, 27 (2006) 20-22.

[5] C.T. Wang, L.Q. Ma, M.Y. Yin, Z.Y. Liu, Y. Ding, H. Zhang, Y.G. Chen. Effects of SiC Particles oxidation on the wettability and interfacial bonding of SiC-p/Al composites [J].Special Casting \& Nonferrous Alloys, 30 (2010) 1062-1065. 
[6] Z.Q. Yu, G.H. Wu, L.T. Jiang. Effect of surface modification of sub-micron Al2O3 particles by rare-earth on interfacial wettability of Al matrix composites [J].The Chinese Journal of Nonferrous Metals, 15 (2005) 1087-1091.

[7] N.P. Cheng, S.M. Zeng, Z.Y. Liu. Preparation, microstructures and deformation behavior of $\mathrm{SiCP} / 6066 \mathrm{Al}$ composites produced by PM route [J]. Journal of Materials Processing Technology, 202(2008) 27-40.

[8] T.X. Fan, D. Zhang, G. Yang, T. Shibayanagi, M. Naka, T. Sakata, et al. Chemical reaction of Al-SiC composites during multiple remelting[J]. Compos A 34 (2003) 291-299.

[9] P. Liu, A.Q. Wang, S.M. Hao, J.P. Xie. The interfacial condition of SiCp/Al composites [J]. Journal of Chinese Electron Microscopy Society, 33 (2014) 306-312.

[10]W.M. Wang, F.S. Pan, etal. Avance in research on interfacial reaction in SiCp/Al composites [J]. Journal of Chongqing University (NaturalScience Edition), 27 (2004) 108-113. 